\title{
ПОЛИтОЛОГИЯ
}

DOI: http://dx.doi.org/10.15688/jvolsu4.2016.1.14

UDC 327.82

Accepted: 01.02.2016

LBC 66.4

\section{ELECTIONS TO THE EUROPEAN PARLIAMENT THROUGH THE PRISM OF SOCIAL MEDIAAS AN ELECTORAL RESOURCE IN EUROPEAN COUNTRIES}

\section{Anna Nikolaevna Katkina}

Postgraduate Student, Department of European Research,

Saint Petersburg State University,

Assistant of Director, Department of State Policy in the Sphere of Children and Youth Education, Ministry of Education and Science of the Russian Federation anna.katkina@gmail.com

Lyusinovskaya St., 51, 117997 Moscow, Russian Federation

\begin{abstract}
This article examines social media as a relatively new tool of electoral and political activity aimed at creating a positive image of political parties and candidates to the European Parliament. In the modern world of politics it is becoming increasingly important due to such factors as the growing number of World Wide Web users, the decline in the traditional media popularity and the rapid spread of new media, as well as the transformation of the Internet space into the platform for active political interactions.

The key role in realizing the task of forming political image belongs to political institutions (parties, state bodies), politicians and social activists, as well as population representatives. The analysis of the efforts of various political subjects in the social media roughly demonstrates three functions of this new phenomenon: social media as a turnout increase tool, as a tool of increasing the recognition of candidates and parties by population; as a tool of informing the population about political and electoral processes in society. Currently, the main obstacle for the strategic research in this area is the fact that social networking technologies are rapidly developing, that embarrasses in making long-term prediction on its use. In spite of the absence of recognized criteria giving the opportunity to evaluate political activity in social media, the key efficiency criteria and success factor is so called "permanent presence" of electoral activity subjects in the Internet.

Key words: elections, European Parliament, European Union, Internet, political institutions, social media, electoral processes.
\end{abstract}

УДК 327.82

Дата поступления статьи: 01.02.2016

ББК 66.4

\section{ВЫБОРЫ В ЕВРОПЕЙСКИЙ ПАРЛАМЕНТ ЧЕРЕЗ ПРИЗМУ СОЦИАЛЬНЫХ МЕДИА КАК ЭЛЕКТОРАЛЬНОГО РЕСУРСА В ЕВРОПЕЙСКИХ СТРАНАХ}

\author{
Анна Николаевна Катькина \\ Аспирант кафедры европейских исследований, \\ Санкт-Петербургский государственный университет, \\ помощник директора Департамента государственной политики в сфере воспитания детей и молодежи, \\ Министерство образования и науки Российской Федерации \\ anna.katkina@gmail.com \\ ул. Люсиновская, 51, 117997 г. Москва, Российская Федерация
}


Аннотация. В данной статье рассматривается феномен социальных медиа как относительно новый инструмент электоральной и политической деятельности, направленный на формирование положительного имиджа политических партий и кандидатов от них в Европейский парламент. Они приобретают все большее значение в современной мировой политике в связи с ростом количества пользователей Всемирной сети, падением популярности традиционных СМИ и стремительным распространением новых медиа, а также превращением интернет-пространства в площадку для активных политических действий.

Основная роль в реализации задачи формирования политического имиджа принадлежит политическим институтам (партиям, государственным ведомствам), отдельным политикам и общественным деятелям, а также представителям электората, то есть населению. Анализ усилий различных политических субъектов в социальных медиа позволяет условно выделить три функции: социальные медиа как инструмент повышения явки на выборы; инструмент повышения узнаваемости кандидатов и партий среди населения; способ повышения информированности населения о политических и электоральных процессах, происходящих в обществе в целом. В настоящее время серьезным препятствием для стратегических исследований в данной сфере является то, что технологии социальных сетей развиваются колоссальными темпами, что затрудняет какиелибо долгосрочные прогнозы относительно их использования. Несмотря на отсутствие общепризнанных критериев, позволяющих оценить эффективность ведения политической деятельности в социальных медиа, ключевым критерием и фактором успеха определено так называемое «постоянное присутствие» субъектов электоральной деятельности в сети Интернет.

Ключевые слова: выборы, Европейский парламент, Европейский союз, Интернет, политические институты, социальные медиа, электоральные процессы.

В последнее время все чаще говорят о влиянии социальных медиа как на политические процессы, так и общество в целом. Роль и функции медиа необратимо меняются, а технологии коммуникаций развиваются потрясающими темпами. На смену «оранжевой», «бархатной» и прочим «цветным революциям» приходят революции Ближнего Востока, организованные с помощью социальных медиа, таких как Twitter и Facebook.

Впервые появившись в 2003 г., социальные сети с каждым годом становились все популярнее. Количество пользователей социальных медиа растет в геометрической прогрессии, но влияние данного феномена на происходящие в обществе политические процессы еще не полностью исследовано, что позволяет говорить об актуальности темы.

Социальные медиа являются мощным ресурсом, нередко определяющим направление и результат различных электоральных процессов, происходящих в современном мире. Выявление и изучение функций, которые выполняют социальные медиа, позволит более четко определить их место в политической жизни общества и выявить механизм социальных изменений в данной сфере.

В силу своей новизны характер и степень влияния социальных медиа на электоральные процессы еще недостаточно изучены. Следует отметить, что тему воздействия медиа и, в частности, СМИ на общество не обошли своим вниманием такие российские исследователи, как исполнительный директор Национальной ассоциации массмедиа исследователей (НАММИ) И.В. Жилавская [4], профессор Высшей школы экономики, член Редакционного совета Российской Коммуникативной ассоциации И.М. Дзялошинский [3], декан факультета журналистики Московского государственного университета им. М.В. Ломоносова, доктор филологических наук, професcop Е.Л. Вартанова [1] и др.

В настоящее время все больше подтверждается тезис о том, что социальные медиа помимо того, что играют ключевую роль в политических процессах, также выполняют важнейшие функции, способствующие развитию института выборов в целом. Социальные медиа представляют собой категорию вебсайтов, предоставляющих возможность публикации, обмена и обсуждения контента широким кругом пользователей. В июне 2009 г. Twitter использовали более 50 миллионов человек. На сегодняшний день им пользуются более 250 миллионов. Количество пользователей Facebook возросло с 200 миллионов пользователей в период последних выборов в Европейский парламент до более 1 миллиарда на сегодняшний день [5]. Нужно отметить, что абсолютное большинство евродепутатов и политических партий имеют свои «accounts» 
в Facebook и Twitter, в которых они делятся своими политическими идеями и где они призывают граждан приходить на избирательные участки. Например, аккаунт в Twitter немецкого политика, члена Партии европейских социалистов, председателя Европарламента (с 17 января 2012 г. по настоящее время) Мартина Шульца на 10 октября 2015 г. насчитывал более 205 тысяч подписчиков [14]. Помимо личного аккаунта, Мартин Шульц имеет еще и «служебный» [6], который ведет его пресс-служба. Количество этого аккаунта составляет 28 тысяч человек. Стоит отметить, что свой профиль в Twitter активно ведет и немолодой уже (75 лет) польский политик, экспредседатель Европарламента (с 2009 по 2012 гг.), а ныне депутат Европарламента Ежи Кароль Бузек [13]. Количество подписчиков на его аккаунт в Twitter превышает количество подписчиков Мартина Шульца и составляет 278 тысяч человек. Несомненным минусом является то, что аккаунт Ежи Бузека содержит информацию в основном на польском языке, что, безусловно, сильно ограничивает целевую аудиторию политика.

В электоральных процессах социальные медиа выполняют самые различные функции. Первая из интересующих нас - инструмент для увеличения явки избирателей.

Необходимо отметить, что из руководящих органов Европейского Союза граждане имеют право избирать только депутатов Европейского парламента, но не членов Европейской комиссии, Суда Европейского Союза или иных структур управления. 751 место в Европарламенте представители европейских партий занимают пропорционально набранным на выборах голосам. Затем депутаты формируют общеевропейские политические партии. Исход голосования непосредственно сказывается на жизни 500 миллионов жителей европейского континента.

Начиная с 1979 г. участие в выборах в Европарламент по сравнению с предыдущим периодом последовательно падало. По мере того как люди все меньше понимали действия Евросоюза, они все меньше голосовали, и подчас даже не знали «своих» членов Европарламента [11]. Последовательно падал уровень заинтересованности в политическом участии, важности принадлежности к политической партии, падал уровень доверия к решениям политиков. Так, по данным 2012 г., 82 \% граждан Великобритании склонны не доверять правительству, и лишь 26 \% граждан считают, что члены парламента действительно намерены хорошо работать [17, p. 5].

Такая ситуация в странах Европы была названа демократическим дефицитом. Впервые термин употребляется еще в 1977 г. в Манифесте молодых европейских федералистов (Young European Federalists), и с тех пор феномен все более активно обсуждается [16].

Показательным примером демократического дефицита служит Великобритания. Британская молодежь считает традиционные формы политического участия не оправдавшими себя, а новые не использует в силу выключенности из политического пространства $[17$, p. 6]. Эта ситуация не уникальна: очень похожие тенденции можно наблюдать во многих странах Европы.

Падение уровня политического участия в Европе с неизбежностью поставило вопрос о недостатке демократической легитимности самого Евросоюза. Поведение электората становилось все более непредсказуемым, уровень избирательной активности все более низким. Соответственно, сегодня большинство политиков Евросоюза стоит перед задачей обратить этот тренд вспять, наладить контакт и снова войти в коммуникацию со своим избирателем. Политические партии нуждаются в профессионализации коммуникации, развитии новых инструментов ведения кампаний, в новых коммуникационных стратегиях для достижения избирателя. Именно поэтому для стран Европы ресурс Интернета сегодня имеет очевидную ценность как минимум из-за возможности быстрого и эффективного объединения большого числа разрозненных невовлеченных избирателей. Бурное развитие инструментов политического Web 2.0 приходится в Европе на очередной виток решения болезненного вопроса о «демократическом дефиците» в странах Евросоюза.

На выборах в Европейский парламент в 2004 г. в Германии был установлен своеобразный антирекорд: явка избирателей составила $43 \%$. Такой показатель оказался самым низким за всю историю выборов в представительный орган Европейского Со- 
юза. Ожидалось, что на выборах 2009 г. она будет еще ниже.

Как следствие, в 2009 г. в преддверии выборов в Европейский парламент политики, опасаясь низкой явки избирателей, особенно из числа молодежи, обратились к электорату через популярные интернет-ресурсы, такие как Facebook и Twitter.

Перед выборами в Европейский парламент социальные медиа были объявлены основным инструментом повышения явки, привлечения поддержки и популяризации выборов (особенно среди европейских политических партий).

Уже тогда для привлечения электората на выборы и повышения интереса молодежи к политике в целом руководство Европейского парламента приняло решение создать собственные виртуальные профили на популярных среди молодежи интернет-порталах. В то время появилась собственная страница Европейского парламента в социальных сетях Facebook [7] и MySpace [9].

Социальные медиа предлагают политикам и избирателям уникальный инструмент, обеспечивающий прямой доступ друг к другу. Политики используют их в надежде получить поддержку (хотя вопрос привлечения новых единомышленников остается спорным, поскольку многие пользователи изначально следят за профилями в социальных сетях тех политиков, с взглядами которых они уже согласны).

С одной стороны, представляется целесообразным провести параллель между соответствием стран с высоким уровнем активности в социальных медиа в процессе выборов (в зависимости от общей численности населения, регулярно использующего социальные медиа) и увеличением явки, но, похоже, такое соответствие установить не представляется возможным.

Например, широкое обсуждение выборов в интернет-пространстве происходило во Франции, Финляндии и Испании, и явка в этих странах заметно повысилась. Но аналогичная активность не увеличила явку на выборах в Италии (хотя на 60 \% такая активность была выше, чем во многих других странах). Несмотря на более скромное обсуждение выборов в социальных медиа в Литве и Греции, явка в этих странах увеличилась более чем где-либо.
Существует также значительное число исследований, демонстрирующих, что по крайней мере в национальных выборах социальные медиа сыграли огромную роль. Исследование, проведенное в США в ноябре 2010 г., охватившее порядка 61 миллиона пользователей Facebook, показало, что люди охотнее голосуют, увидев сообщение о том, что их друзья уже проголосовали с помощью кнопки «Я голосовал». Так, 2 ноября 2010 г., в день выборов в Конгресс США, более 60 миллионов пользователей Facebook в США увидели наверху своей страницы сообщение с призывом проголосовать, размещенное командой исследователей из Калифорнийского университета в Сан-Диего. По результатам исследования было установлено, что пользователи были на $1,8 \%$ более склонны проголосовать, если видели, что их близкие друзья также просмотрели сообщение [12].

Facebook использовал подобный инструмент и на прошедших выборах в Европейский парламент, и сообщение «Я голосовал» видели почти 90 миллионов человек (хотя не установлено за какой период времени).

Таким образом, при условии грамотно выстроенной коммуникации с пользователем социальные сети могут стать дешевым и эффективным средством в достижении цели привлечения граждан на избирательный участок.

В конечном счете сам факт того, что масштаб обсуждений генерируется на площадках различных социальных медиа, а не только в Facebook, свидетельствует о заинтересованности кандидатов и политических институтов в расширении своего присутствия в социомедийном пространстве.

Консалтинговая компании BursonMarsteller, являющаяся лидером на рынке связей с общественностью и коммуникаций, проанализировала около трех миллионов записей в Twitter о выборах в Европейский парламент. Более миллиона записей о выборах [без использования «официального» хэштега (хэштег с англ. hashtag - «метка») \#ЕР2014] были отправлены в течение одной недели во время выборов, и половина из них была отправлена в воскресенье 25 мая (в последний день выборов), но сотни тысяч сообщений о выборах достигли целевой аудитории в миллионы людей через социальные медиа. 
Европейский парламент опубликовал также статистические данные, в соответствии с которыми количество просмотров видеоролика, призывающего к голосованию, достигло 11 миллионов. Таким образом, следует признать, что обсуждение электоральных процессов в социальных сетях способствует большей осведомленности и информированности населения о выборах, росту интереса населения и повышает явку.

В качестве второй функции стоит обозначить повышение узнаваемости. Помимо увеличения явки, социальные медиа являются незаменимым инструментом для формирования имиджа и повышения узнаваемости кандидатов и политических институтов среди населения.

В рамках подготовки к выборам в Европейский парламент 2014 г. на дискуссии, организованной представительством Европейского парламента в Великобритании в ноябре 2013 г., активно обсуждалась роль социальных медиа в электоральных процессах, в частности вопрос влияния социальных медиа на выбор избирателей.

Члены Европарламента Ричард Хауит (Прогрессивный альянс социалистов и демократов Европейского парламента, Лейбористская партия Парламента Великобритании) и Карен Мельхиор (кандидат в депутаты от Альянса либералов и демократов за Европу, партия социал-демократов Дании) рассказали о своем взаимодействии с электоратом посредством социальных медиа. Упомянув об отсутствии возможности отвечать всем, кто им писал, парламентарии вместе с тем выразили мнение, что социальные медиа, несомненно, усилили взаимодействие членов Европейского парламента, кандидатов в депутаты и избирателей по волнующим их социально значимым вопросам.

По словам Карен Мельхиор, она не верила в возможность стать кандидатом в Европейский парламент, так как была убеждена, что не может быть активно и постоянно вовлечена в общение посредством социальных медиа.

Наиболее компетентным «сетевым» политиком Европы уже последние несколько лет считается голландский член Европарламента Мариедже Шааке (Marietje Schaake). По сути, она стала одним из первых европейских политиков, кто признал и понял ценность и важность социальных медиа. Своим избранием она также обязана Интернету - придя в партию на должность стратега новых медиа, спустя какое-то время она была выдвинута своими же коллегами кандидатом на предстоящих выборах. По ее признанию, ни бюджета, ни стратегии у нее не было, зато были сторонники в сети, а также сформированная молодая аудитория Facebook и Twitter и понимание происходящих процессов. На сегодняшний момент именно она является тем голосом, который критикует европейскую фиксацию на защите прав и озвучивает точку зрения о том, что Европа застряла в дискуссии о том, как защитить свои интернет-границы, а контент-индустрия позволяет деньгам утекать в США.

Она также активно занимается образовательной деятельностью среди членов Европарламента, поскольку, «если вы не знаете, что такое API, вы не должны быть среди тех, кто пишет об этом законы», а по ее утверждению, едва ли найдется хоть один член парламента, который сможет внятно объяснить, что это [15].

При изучении процессов, происходящих непосредственно после выборов, необходимо отметить важность дальнейшего взаимодействия депутатов и политических институтов с населением посредством социальных медиа. Депутаты и политические партии должны продолжать информировать и взаимодействовать с гражданами в социальных сетях. В конце концов, вопросы демократии и законности не заканчиваются у избирательной урны, поэтому нужно позволить гражданам быть более вовлеченными в политику и быть «на связи» с политиками и организациями, чтобы подкрепить легитимность их представительности [18].

В этой связи обозначим третью ключевую функцию - повышение информированности населения о политических и электоральных процессах в обществе.

Энди Вильямсон, всемирно признанный эксперт в области цифровой демократии, выделяет вопрос политической неграмотности населения как отдельную социальную проблему. Он отмечает, что в настоящее время уро- 
вень осведомленности и заинтересованности граждан Европейского Союза в участии в политической жизни весьма низок, и только абсолютное меньшинство обучающихся заканчивают школу или университет, будучи уверенными в своей возможности изменить существующую политическую ситуацию [5]. Именно поэтому политикам не следует упускать из виду то мнение, которое население Европы выражает с помощью социальных медиа, но необходимо помнить, что это мнение не всегда компетентно.

Вместе с тем Тони Коуэн-Браун, стратег в области цифровых технологий ведущей мировой консалтинговой компании в области связей с общественностью и коммуникаций Burson-Marsteller (филиал в Европе, на Ближнем Востоке и в Африке), отмечает: «...существующая система образования не способна идти в ногу со временем. Некоторым посчастливилось получить политическое образование и в университете, и дома. С годами я стала использовать социальные медиа, такие как Twitter, с целью самообразования, чтобы быть образованным на политические темы среди прочих других - но многие упускают знания, понимание и интерес, чтобы пользоваться своими демократическими правами эффективно» [5].

Безусловно, одним из самых очевидных решений проблемы политической неграмотности населения является использование социальных медиа. Они способствуют повышению информированности населения о политических и электоральных процессах, их осознанию и пониманию, а также популяризации среди населения. Чтобы собрать большую аудиторию, занимаясь политикой - и особенно европейской политикой, которая часто бывает чуждой относительно людских судеб - необходимы огромные усилия.

Официальный профиль Европейского парламента существует и на фотобирже Flickr [8], а также на популярном видеохостинге YouTube [10]. На первом ежедневно в течение всей предвыборной кампании 2009 г. публиковались официальные фотографии организации, на втором на специальном канале EU Tube помещались видеозаписи, посвященные выборам и деятельности Европейского парламента. Пользователи, в свою очередь, также имеют возможность обращаться к евродепутатам с видеопосланиями, разместив их в профиле EU Tube [2].

Посетители, обратившиеся к одному из новых интернет-ресурсов Европейского парламента, могут узнать много интересного о деятельности представительного и законодательного органа Европейского Союза. Так, например, на ресурсе Европейского парламента на хостинге YouTube размещена информация о действиях депутатов, предпринимаемых для снижения тарифов на мобильную связь или СМС-сообщений, реформах в сфере образования. Кроме того, на примере двух «виртуальных домов» 1979 и 2009 гг. посетители могут наглядно увидеть, как изменился Европейский Союз за последние годы и какое влияние эти изменения оказали на их собственную жизнь.

Немаловажен и тот факт, что посетители сайтов получают возможность дать свой отклик на публикации, например, отправить свои видеозаписи депутатам или через форум вступить с ними в дискуссии по вопросам деятельности Евросоюза и его институтов [2].

Конвертация осознания происходящих в политической жизни общества процессов в интерес и интереса в избирательные голоса имеет решающее значение. Возможно, социальные медиа не станут единственным средством для преодоления разрыва между появлением осознанности и зарождением интереca, но они, несомненно, являются ключевой частью решения [5].

Несмотря на то что социальные медиа играют важную роль в различных сферах жизни общества, сфера политики подвержена их влиянию не в меньшей мере, нежели остальные. Однако технологии социальных сетей развиваются колоссальными темпами, что затрудняет какие-либо долгосрочные прогнозы относительно их использования. Кандидаты в члены Европейского парламента и политические институты должны быть все время во взаимодействии с электоратом не только до, но и после выборов. Это так называемое «постоянное присутствие» в социальных сетях и определено ключевым фактором успеха и критерием эффективности. В этой связи наиболее успешными и, как следствие, имеющими большие шансы на победу в выборах 
становятся те политические фигуры, которые только повышают и углубляют свое присутствие в социальных медиа, делают его более качественным и эффективным, ведут в социальных сетях двусторонний диалог.

\section{СПИСОК ЛИТЕРАТУРЫ}

1. Вартанова, Е. Л. Медиаэкономика зарубежных стран : учеб. пособие / Е. Л. Вартанова. - М. : Аспект Пресс, 2003. - 336 с.

2. Грудинина, М. Европарламент обосновался в социальных сетях / М. Грудинина // Русская редакция Deutsche Welle. - 2009. - Электрон. текстовые дан. - Режим доступа: http://www.dw.de/европарламент-обосновался-в-социальных-сетях/a-4264666 (дата обращения: 05.09.2014). - Загл. с экрана.

3. Дзялошинский, И. М. Журналистика соучастия. Как сделать СМИ полезными людям? / И. М. Дзялошинский. -М. : Престиж, 2006. - 104 с.

4. Жилавская, И. В. Информальные медиа / И. В. Жилавская // Медиаобразование: от теории - к практике : сб. материалов Всерос. науч.практ. конф. «Медиаобразование в развитии науки, культуры, образования и средств массовой информации» (г. Томск, 20-21 нояб. 2007 г.). Электрон. текстовые дан. - Режим доступа: http:/ /www.4cs.ru/materials/wp-id_396 (дата обращения: 09.03.2012). - Загл. с экрана.

5. Cowan-Brown, T. Will the EU get a social media election? / T. Cowan-Brown // Europe Decides. -2013. Electronic text data. - Mode of access: http:// europedecides.eu/2013/12/will-the-eu-get-a-social-mediaelection (date of access: 17.09.2014). - Title from screen.

6. EP President // Twitter. - Electronic data. Mode of access: https://twitter.com/EP President (date of access: 07.09.2015). - Title from screen.

7. European Parliament//Facebook. - Electronic data. - Mode of access: https://www.facebook.com/ europeanparliament (date of access: 15.09.2014). - Title from screen.

8. European Parliament//Flickr.-Electronic data.Mode of access: https://www.flickr.com/photos/european parliament (date of access: 09.08.2014). - Title from screen.

9. European Parliament // My Space. - Electronic data. - Mode of access: https://myspace.com/ europeanparliament (date of access: 15.09.2014). - Title from screen.

10. European Parliament// YouTube. - Electronic data. - Mode of access: http://www.youtube.com/ user/EuropeanParliament (date of access: 17.09.2014). - Title from screen.

11. Ford, M. Europe's Democratic Deficit Is Getting Worse / M. Ford // The Atlantic. - 2014. Electronic text data. - Mode of access: http:// www.theatlantic.com/international/archive/2014/05/ europes-democratic-deficit-is-getting-worse/371297/ (date of access: 06.09.2015). - Title from screen.

12. Giles, J. How Facebook could help swing the US election/ J. Giles // New Scientist. - 2012. - Electronic text data. - Mode of access: http://www.newscientist. com/article/dn22261-how-facebook-could-help-swingthe-us-election.html\#.VFQ6p_msWSo (date of access: 12.09.2014). - Title from screen.

13. Jerzy Buzek // Twitter. - Electronic data. Mode of access: https://twitter.com/jerzybuzek (date of access: 10.10.2015). - Title from screen.

14. Martin Schulz // Twitter. - Electronic data. Mode of access: http://europedecides.eu/2014/06/ social-media-and-the-elections-did-it-have-an-impact/ (date of access: 10.10.2015). - Title from screen.

15. Rooney, B. Europe's Most Wired Politician / B. Rooney // The Wall street journal. - 2011. Electronic text data. - Mode of access: http://blogs. wsj.com/tech-europe/2011/06/17/marietje-schaakeeuropes-most-wired-politician/ (date of access: 01.09.2015). - Title from screen.

16. The first use of the term «democratic deficit». // Federal union. - 1977. - Electronic text data. - Mode of access: http://www.federalunion.org.uk/the-firstuse-of-the-term-democratic-deficit (date of access: 05.09.2015). - Title from screen.

17. Virtually members: the Facebook and Twitter followers of UK political parties / J. Bartlett, S. Bennett, R. Birnie, S. Wibberley // Demos. - 2013. - Electronic text data. - Mode of access: http://www.demos.co.uk/ files/Virtually_Members.pdf?1366125743 (date of access: 05.09 .2015 ). - Title from screen.

18. Zaremba-Pike, M. Social media and the elections - did it have an impact? / M. Zaremba-Pike // Europe Decides. - 2014. - Electronic text data. Mode of access: http://europedecides.eu/2014/06/ social-media-and-the-elections-did-it-have-an-impact/ (date of access: 17.09.2014). - Title from screen.

\section{REFERENCES}

1. Vartanova E.L. Mediaekonomika zarubezhnykh stran [Media Economics of Foreign Countries]. Moscow, Aspekt Press, 2003. 336 p.

2. Grudinina M. Evroparlament obosnovalsya v sotsialnykh setyakh [European Parliament Settled in Social Networks]. Deutsche Welle (Russian Edition), 2009. Available at: http://www.dw.de/европарламентобосновался-в-социальных-сетях/а-4264666. (accessed September 5, 2014).

3. Dzyaloshinskiy I.M. Zhurnalistika souchastiya. Kak sdelat SMI poleznymi lyudyam? [Journalism of Complicity. How to Make Mass Media Useful for People?]. Moscow, Prestizh Publ., 2006. 104 p. 
4. Zhilavskaya I.V. Informalnye media [Informal Media]. Mediaobrazovanie: ot teorii $-k$ praktike, sbornik materialov Vserossiyskoy nauchnoprakticheskoy konferentsii "Mediaobrazovanie v razvitii nauki, kultury, obrazovaniya i sredstv massovoy informatsii" [Mediaeducation - From Theory to Practice. Proceedings of All-Russian Scientific Practical Conference "Media Education in the Development of Science, Culture, Education and Media"]. Tomsk, 2007, November 20-21. Available at: http://www.4cs.ru/materials/wp-id_396. (accessed March 9, 2012).

5. Cowan-Brown T. Will the EU Get a Social Media Election? Europe Decides, 2013. Available at: http://europedecides.eu/2013/12/will-the-eu-get-asocial-media-election. (accessed September 17, 2014).

6. EP President. Twitter. Available at: https:// twitter.com/EP_President. (accessed September 7, 2015).

7. European Parliament. Facebook. Available at: https://www.facebook.com/europeanparliament. (accessed September 15, 2014).

8. European Parliament. Flickr. Available at: https://www.flickr.com/photos/european_parliament. (accessed August 9, 2014).

9. European Parliament. My Space. Available at: https://myspace.com/europeanparliament. (accessed September 15, 2014).

10. European Parliament. YouTube. Available at: http://www.youtube.com/user/EuropeanParliament. (accessed September 17, 2014).

11. Ford M. Europe's Democratic Deficit Is Getting Worse. The Atlantic, 2014. Available at: http:/ /www.theatlantic.com/international/archive/2014/05/ europes-democratic-deficit-is-getting-worse/371297/. (accessed September 6, 2015).

12. Giles J. How Facebook Could Help Swing the US Election. New Scientist, 2012. Available at: http:// www.newscientist.com/article/dn22261-how-facebookcould-help-swing-the-us-election.html\#.VFQ6p_ msWSo. (accessed September 12, 2014).

13. Jerzy Buzek. Twitter. Available at: https:// twitter.com/jerzybuzek. (accessed October 10, 2015).

14. Martin Schulz. Twitter. Available at: http:// europedecides.eu/2014/06/social-media-and-theelections-did-it-have-an-impact/. (accessed October 10, 2015).

15. Rooney B. Europe's Most Wired Politician. The Wall street journal, 2011. Available at: http:// blogs.wsj.com/tech-europe/2011/06/17/marietjeschaake-europes-most-wired-politician/. (accessed September 1, 2015).

16. The First Use of the Term "Democratic Deficit”. Federal union, 1977. Available at: http:// www.federalunion.org.uk/the-first-use-of-the-termdemocratic-deficit. (accessed September 5, 2015).

17. Bartlett J., Bennett S., Birnie R., Wibberley S. Virtually Members: the Facebook and Twitter Followers of UK Political Parties. Demos, 2013. Available at: http://www.demos.co.uk/files/ Virtually_Members.pdf?1366125743. (accessed September 5, 2015).

18. Zaremba-Pike M. Social Media and the Elections - Did It Have an Impact? Europe Decides, 2014. Available at: http://europedecides.eu/2014/06/ social-media-and-the-elections-did-it-have-an-impact/. (accessed September 17, 2014). 